\title{
Effects of butter naturally enriched with conjugated linoleic acid and vaccenic acid on blood lipids and LDL particle size in growing pigs
} Anna Haug*1, Per Sjøgren ${ }^{2}$, Nina Hølland ${ }^{1}$, Hanne Müller ${ }^{1}$, Nils P Kjos ${ }^{1}$, Ole Taugbøl ${ }^{1}$, Nina Fjerdingby ${ }^{3}$, Anne S Biong ${ }^{4}$, Eirik Selmer-Olsen ${ }^{4}$ and Odd M Harstad ${ }^{1}$

\author{
Address: ${ }^{1}$ Dept of Animal and Aquacultural Sciences, Norwegian University of Life Sciences, Aas, Norway, ${ }^{2}$ King Gustaf V Research Institute, \\ Karolinska Institute, Stockholm, Sweden, ${ }^{3}$ Norwegian School of Veterinary Science, Oslo, Norway and ${ }^{4}$ Tine BA, Oslo, Norway \\ Email: Anna Haug* - anna.haug@umb.no; Per Sjøgren - per.sjogren@medks.ki.se; Nina Hølland - ninahoelland@hotmail.com; \\ Hanne Müller - hanne.muller@hit.no; Nils P Kjos - nils.kjos@umb.no; Ole Taugbøl - ole.taugbol@umb.no; \\ Nina Fjerdingby - nina.fjerdinbgy@veths.no; Anne S Biong - anne.sofie.biong@tine.no; Eirik Selmer-Olsen - eirik.selmer-olsen@tine.no; \\ Odd M Harstad - odd.harstad@umb.no \\ * Corresponding author
}

Published: 29 August 2008

Lipids in Health and Disease 2008, 7:31 doi:10.1I86/1476-5IIX-7-31

This article is available from: http://www.lipidworld.com/content/7/I/3I

(c) 2008 Haug et al; licensee BioMed Central Ltd.

This is an Open Access article distributed under the terms of the Creative Commons Attribution License (http://creativecommons.org/licenses/by/2.0), which permits unrestricted use, distribution, and reproduction in any medium, provided the original work is properly cited.
Received: 27 June 2008

Accepted: 29 August 2008

\begin{abstract}
Background: Cow milk is a natural source of the cis 9 , trans II isomer of conjugated linoleic acid (c9,tl I-CLA) and trans vaccenic acid (VA). These fatty acids may be considered as functional foods, and the concentration in milk can be increased by e.g. sunflower oil supplementation to the dairy cow feed.

The objective of this study was to compare the effects of regular butter with a special butter naturally enriched in $c 9, \mathrm{t}$ I I-CLA and VA on plasma lipids in female growing pigs. The experimental period lasted for three weeks and the two diets provided daily either $5.0 \mathrm{~g} \mathrm{C9,tl} \mathrm{I-CLA} \mathrm{plus} 15.1 \mathrm{~g}$ VA or $1.3 \mathrm{~g}$ c $9, \mathrm{t} \mathrm{I} \mathrm{I}-\mathrm{CLA}$ plus $3.6 \mathrm{~g}$ VA.

Results: The serum concentrations of $\mathrm{c} 9, \mathrm{tI}$ I-CLA, VA and alpha-linolenic acid were increased and myristic (14:0) and palmitic acid (16:0) were reduced in the pigs fed the CLA+VA-rich butter-diet compared to regular butter, but no differences in plasma concentrations of triacylglycerol, cholesterol, HDL-cholesterol, LDL-cholesterol, LDL particle size distribution or total cholesterol/ HDL cholesterol were observed among the two dietary treatment groups.

Conclusion: Growing pigs fed diets containing butter naturally enriched in about $20 \mathrm{~g} \mathrm{c9,t} \mathrm{I} \mathrm{-CLA}$ plus VA daily for three weeks, had increased serum concentrations of alpha-linolenic acid and decreased myristic and palmitic acid compared to pigs fed regular butter, implying a potential benefit of the CLA+VA butter on serum fatty acid composition. Butter enriched in CLA+VA does not appear to have significant effect on the plasma lipoprotein profile in pigs.
\end{abstract}

\section{Background}

Milk and dairy products have long traditions in human nutrition, but for some decades milk fat has been associ- ated with negative health effects. However, the association between milk fat and plasma lipids is ambiguous, and a paradox. Several studies show no convincing evidence 
that dairy products increase the risk of cardiovascular disease and that milk is harmful [1-4]. Some studies indicate that a moderate intake of milk fat may reduce the risk of cardiac diseases, possibly through reduced formation of small dense low density lipoprotein particles (sdLDL) [5]. The sdLDL are thought to undergo oxidation more readily, or to be harder bound to the arterial endothelia surface [6]. Dairy milk fat contains numerous fatty acids that might affect formation of sdLDL, such as saturated fatty acids, c9,t11-CLA isomer and VA [7,8]. Evidence for hypolipidemic properties of $\mathrm{C} 9, \mathrm{t} 11$-CLA has been given, and administration of CLA has been shown to modulate plasma lipid concentration in both human and animal models, and to reduce markers associated with atherogenic risk [8-10]. These findings have led to considerable interest in methods for naturally increasing the $\mathrm{c} 9, \mathrm{t} 11$ CLA content in milk, and milk products that are naturally enriched in CLA has been advocated. CLA is a group of polyunsaturated fatty acids found naturally in beef, lamb and dairy products, and C9,t11-CLA is the main form of CLA $(18: 2 \mathrm{c} 9, \mathrm{t} 11)$. It can be produced in ruminants by bacterial isomerisation of linoleic acid $(18: 2 \mathrm{c} 9, \mathrm{c} 12)$ in the rumen. In ruminants and non-ruminants it can be produced in most tissues by delta- 9 desaturation of VA $(18: 1 \mathrm{t} 11)[11,12]$. The concentration of $\mathrm{c} 9, \mathrm{t} 11$-CLA and VA in milk fat is highly dependent on the feed composition; VA is an intermediate product of biohydrogenation of unsaturated fatty acids in the rumen, and feedstuff rich in linoleic or $\alpha$-linolenic acids enhance CLA and VA in milk [13]. Since c9,t11-CLA in milk fat is associated with $\mathrm{VA}$, milk rich in $\mathrm{C} 9, \mathrm{t} 11$-CLA is also rich in VA, its precursor [12]. In general, trans fatty acids are associated with increased plasma cholesterol and risk for coronary heart disease. Therefore the concentration of VA in milk has been of concern. However, VA's effect on plasma cholesterol has not been entirely understood since epidemiological studies have shown that trans fatty acids from animal sources did not increase risk for coronary artery disease [14].

The objective of the study presented here was to compare effects on plasma lipid- and fatty acid profile in growing pigs that had been given diets containing regular butter (REG) or butter naturally enriched in CLA plus VA.

\section{Results and discussion}

\section{Feed intake and weight gain}

In the present study, there were no significant differences in the feed intake (in average $1.65 \mathrm{~kg}$ and $1.67 \mathrm{~kg}$ per day), weight gain $(17.9 \mathrm{~kg}$ and $18.4 \mathrm{~kg}$ ) and final body weight $(61.2 \mathrm{~kg}$ and $61.9 \mathrm{~kg}$ ) in the REG and CLA+VA treatment groups, respectively (data not shown). The CLA isomer involved in decreasing body fat is the t10,c12-CLA isomer, but there are no concluding evidence of such effects of the C9,t11-CLA isomer $[15,16]$.

\section{Fatty acid (FA) composition of diets}

The CLA+VA rich butter diet differed from the regular butter diet with a higher concentrations of c9,t11-CLA, VA, oleic acid (18:1,9c), linoleic (18:2) and $\alpha$-linolenic acid (18:3), and less 10:0, 12:0, myristic acid and palmitic acid (Table 1). This diet provided daily $5.0 \mathrm{~g}$ CLA and $15.1 \mathrm{~g}$ VA, and the intake of these two fatty acids was about four times higher in the CLA+VA dietary treatment compared to the REG dietary treatment. Intake of CLA+VA as percent of average body weight was about $0.04 \%$ in the CLA+VA treatment group, and $0.01 \%$ in the REG group. Alphalinolenic acid was about 30\% higher and palmitic and myristic acid about 25\% lower in the CLA+VA diet compared to REG.

To provide a high intake of natural CLA and VA, the experimental diets were rich in fat; $19 \%$ fat in both diets, giving as much as $46 \%$ of the energy (E\%) from fat. The pigs liked the diets, and in accordance to others [17] pigs tolerated well a high fat diet.

\section{Serum fatty acids}

At the start of the experiment there were no differences between the two experimental groups in the concentration of different FA in serum (data not shown). In contrast, at the end of the study it was significant differences between the diet groups in concentration of several serum FA (Table 2).

Table I: Fatty acid composition of the diets, $(\mathrm{g} / 100 \mathrm{~g}$ fatty acid methyl ester).

\begin{tabular}{lrr}
\hline Fatty acid & REG $^{\mathrm{a}}$ & $\mathrm{CLA}+\mathrm{VA}^{\mathrm{b}}$ \\
\hline $10: 0$ & 2.43 & 1.61 \\
$12: 0$ & 2.88 & 2.13 \\
$14: 0$ & 10.32 & 8.02 \\
$14: 1$ & 0.93 & 0.79 \\
$16: 0$ & 28.09 & 20.84 \\
$16: 1$ & 1.65 & 1.13 \\
$18: 0$ & 11.09 & 10.75 \\
$18: 1 \mathrm{tll}$ & 1.36 & 5.62 \\
$18: 19 \mathrm{c}$ & 22.03 & 25.11 \\
$18: 2 \mathrm{n}-6$ & 7.09 & 9.21 \\
$18: 3 \mathrm{n}-3$ & 1.13 & 1.51 \\
$\mathrm{c} 9, \mathrm{tl} \mathrm{I}-\mathrm{CLA}$ & 0.53 & 1.85 \\
$20: 4 \mathrm{n}-6$ & 0.07 & 0.09 \\
$20: 5 \mathrm{n}-3$ & 0.07 & 0.10 \\
$22: 5 \mathrm{n}-3$ & 0.07 & 0.07 \\
$22: 6 \mathrm{n}-3$ & 0.02 & 0.05 \\
& & 88.88 \\
Sumc & 89.80 & \\
\hline
\end{tabular}

aDiet with regular butter as fat supplement

bDiet with CLA+VA rich butter as fat supplement

c Butter contains several unidentified fatty acids in small amounts (areal percent less than 0.5\%). 
Table 2: Overall means in serum fatty acid concentration $(\mathrm{g} / 100$ $\mathrm{g}$ fatty acid methyl ester) ${ }^{\mathrm{a}}$

\begin{tabular}{lccl}
\hline Fatty acid & REG $^{\mathrm{b}}$ & CLA+VAc & $p$ \\
\hline $10: 0$ & $0.17 \pm 0.05$ & $0.12 \pm 0.03$ & 0.08 \\
$12: 0$ & $0.67 \pm 0.44$ & $0.54 \pm 0.13$ & 0.52 \\
$14: 0$ & $1.36 \pm 0.31$ & $1.03 \pm 0.12$ & $0.04^{*}$ \\
$14: 1$ & $0.32 \pm 0.04$ & $0.28 \pm 0.05$ & 0.18 \\
$16: 0$ & $20.1 \pm 0.90$ & $17.1 \pm 0.75$ & $<0.01^{*}$ \\
$16: 1$ & $1.02 \pm 0.17$ & $0.89 \pm 0.13$ & 0.16 \\
$18: 0$ & $16.3 \pm 1.6$ & $14.6 \pm 0.9$ & 0.054 \\
$18: 19 \mathrm{c}$ & $16.2 \pm 1.7$ & $16.2 \pm 0.3$ & 0.98 \\
$18: 2 \mathrm{n}-6$ & $20.0 \pm 1.3$ & $21.6 \pm 2.4$ & 0.20 \\
$18: 3 \mathrm{n}-3$ & $0.81 \pm 0.13$ & $1.02 \pm 0.09$ & $0.01^{*}$ \\
$18: 1 \mathrm{tII}$ & $0.27 \pm 0.05$ & $1.09 \pm 0.18$ & $<0.01^{*}$ \\
$\mathrm{c} 9, \mathrm{tI} \mathrm{I}-\mathrm{CLA}$ & $0.28 \pm 0.08$ & $0.80 \pm 0.07$ & $<0.01^{*}$ \\
$20: 4 \mathrm{n}-6$ & $8.2 \pm 1.0$ & $8.1 \pm 0.4$ & 0.89 \\
$20: 5 \mathrm{n}-3$ & $1.49 \pm 0.19$ & $1.46 \pm 0.06$ & 0.65 \\
$22: 5 \mathrm{n}-3$ & $1.41 \pm 0.15$ & $1.47 \pm 0.19$ & 0.57 \\
$22: 6 \mathrm{n}-3$ & $1.74 \pm 0.34$ & $1.46 \pm 0.17$ & 0.10 \\
\hline
\end{tabular}

a Values given as mean $\pm S D$, and $p$-values, $n=6$.

bDiet containing regular butter as fat supplement

cDiet containing $\mathrm{CLA}+\mathrm{VA}$ rich butter as fat supplement

$* p<0.05$.

The main FA in serum are palmitic acid, stearic acid, oleic acid and linoleic acid, together accounting for about $70 \%$ of total FA (Table 2). Pigs fed the CLA+VA diet had a 3.4 fold higher serum concentrations of $\mathrm{c} 9, \mathrm{t} 11$-CLA plus VA compared to the REG diet group. Alpha-linolenic acid was $25 \%$ higher, and myristic and palmitic acid was $25 \%$ and $15 \%$ lower in the serum of CLA+VA compared to the REG dietary treatment (Table 2). The mirroring effect of dietary FA on serum FA is in accordance to several studies $[5,18,19]$. The favourable increased serum concentrations of the omega- 3 fatty acid $\alpha$-linolenic acid and the decrease in the saturated palmitic and myristic acids may indicate that the CLA+VA rich butter can have a positive role in the western diet.

\section{Plasma cholesterol, triacylglycerol and lipoproteins}

At the start of the study, no differences between the groups were observed for plasma concentrations of total cholesterol, LDL-cholesterol, high density lipoprotein (HDL)cholesterol, sdLDL subclass particle diameter, the ratio between total cholesterol and HDL cholesterol, free fatty acids and triacylglycerol.

The dietary fatty acids in the CLA+VA treatment were more favourable than in the REG diet; i.e. more oleic acid (18:1c9), linoleic acid (18:2 n-6), and $\alpha$-linolenic acid (18:3 n-3), c9,t11-CLA and less myrisitc acid (14:0) and palmitic acid (16:0) [20] (Table 1). In spite of intake of the more favourable fatty acids in the CLA+VA treatment group, the plasma concentration of recognized risk markers for atherosclerosis such as total cholesterol, LDL-cholesterol, sdLDL, the ratio between total cholesterol and
HDL cholesterol and triacylglycerol did not decrease, and HDL-cholesterol was not increased (Table 3). The lack of response of CLA+VA enriched butter on lipoprotein profiles is in accordance to a human study [9]. It is also shown no response on plasma lipoproteins in growing pigs fed diets containing unsaturated plant fatty acids compared to saturated animal fat [21]. In the present experiment the two types of butter differed in several fatty acids. Butter contains numerous fatty acids in minor amounts that may have potential bioactive effects on lipid metabolism. The CLA+VA butter contained a high concentration of VA. The intake of VA was considerable in the CLA+VA group; $15.1 \mathrm{~g}$ per day compared to $3.6 \mathrm{~g}$ per day in REG treatment group. Vaccenic acid is a substrate for c9,t11-CLA in the animals own tissue, and in this way it is desirable [11], but trans fatty acids in general has been attributed to increased plasma cholesterol and also other pathogenetic factors $[20,22]$. Given the high dosage of VA supplied daily in the CLA+VA diet, it can not be excluded that VA might have had opposite effects on plasma lipoproteins than CLA and other desirable fatty acids. It has been reported by others that the natural combination of CLA and VA had no detrimental effect on the blood lipid profile in humans [9]. The fact that the high intake (about $20 \mathrm{~g}$ per day for pigs weighing in average about $50 \mathrm{~kg}$ ) of CLA+VA in combination improved serum fatty acid profile and did not have an unfavorable effect of plasma lipoproteins can stimulate to new strategies to develop natural CLA+VA rich dairy products.

Milk products have been shown to have an apparently beneficial effect on LDL particle size distribution (giving less of the sdLDL) [5]. From the Framingham Offspring Study [23] it has been shown that subjects with a high

Table 3: Plasma lipids, lipoproteins and percent distribution of LDL-particles LDL-I, LDL-II, LDL-III and LDL-IVa

\begin{tabular}{|c|c|c|}
\hline & REG ${ }^{b}$ & $\mathrm{CLA}+\mathrm{VA}^{\mathrm{c}}$ \\
\hline Triglyceride & $0.43 \pm 0.07$ & $0.46 \pm 0.13$ \\
\hline Total cholesterol mmol/l & $3.61 \pm 0.5$ & $3.50 \pm 0.4$ \\
\hline HDL cholesterol mmol/l & $1.44 \pm 0.17$ & $|.32 \pm 0.2|$ \\
\hline LDL cholesterol (calculated) & $1.98 \pm 0.37$ & $1.97 \pm 0.33$ \\
\hline Total cholesterol/HDL cholesterol & $2.51 \pm 0.15$ & $2.65 \pm 0.28$ \\
\hline LDL cholesterol/HDL cholesterol & $1.38 \pm 0.15$ & $1.49 \pm 0.28$ \\
\hline LDL peak size $(\AA)$ & $243 \pm 3.6$ & $243 \pm 3.2$ \\
\hline \multicolumn{3}{|l|}{ Percent distributiond } \\
\hline LDL-I (\%) & $21.7 \pm 7.1$ & $25.0 \pm 4.0$ \\
\hline LDL-II (\%) & $47.5 \pm 3.4$ & $44.9 \pm 1.9$ \\
\hline LDL-III (\%) & $20.5 \pm 4.2$ & $18.5 \pm 3.3$ \\
\hline LDL-IV (\%) & $8.0 \pm 1.8$ & $9.2 \pm 1.7$ \\
\hline Nonesterified fatty acids mmol/l & $0.48 \pm 0.18$ & $0.41 \pm 0.09$ \\
\hline
\end{tabular}

a Values given as mean $\pm S D, n=6$.

bDiet containing regular butter as fat supplement

cDiet containing CLA+VA rich butter as fat supplement

d Represents the proportions of LDL-I, 27.0-25.0 nm; LDL-II, 25.0-

$23.5 \mathrm{~nm}$; LDL-III, 23.5-22.5 nm; LDL-IV, 22.5-21.0 nm. 
intake of certain saturated fatty acids (4:0-10:0 and myristic acid) abundantly found in milk products, have lowered levels of sdLDL. Other has shown that saturated fatty acids (especially myristic- and palmitic acid) may affect the distribution of the LDL particles, giving more of the large LDLs [24]. The REG diet contained more 10:0, myrisitic and palmitic acid, but no improvement in LDL particle size was observed in the REG diet group.

\section{Conclusion}

A diet containing natural CLA+VA enriched butter resulted in increased serum concentrations of CLA, vaccenic acid and $\alpha$-linolenic acid, and reduced concentration of myristic and palmitic acid in pigs compared to a diet containing regular butter, indicating a potential health benefit of the CLA+VA rich butter. However, no differences in plasma lipoproteins and LDL particle sizes were observed among the two dietary treatment groups following three weeks feeding. It is worth noting that a relatively high intake of the trans fatty acid VA did not result in a detrimental effect on the lipoprotein profile when it was in combination with $\mathrm{c9}, \mathrm{t} 11$-CLA. Perhaps is the combination of fatty acids in milk fat one reason to the milk fat paradox?

\section{Methods}

Animal care

The experimental research on animals followed internationally recognized guidelines. All animals were cared for according to laws and regulations controlling experiments with live animals in Norway (The Animal Protection Act of December 20th, 1974, and the Animal Protection Ordinance Concerning Experiments with Animals of January 15th, 1996); according to the rules given by Norwegian Animal Research Authority.

\section{Animals and diets}

Twelve growing female pigs (initial weight were $43.4 \pm 1.5$ $\mathrm{kg}$ ) of a commercial Norwegian crossbreed ((Landrace $\times$ Yorkshire $) \times($ Landrace $\times$ Duroc $))$ were selected for the study. The pigs were reared indoors, and fed two times per day in accordance to NRC requirements for nutrients for growing pigs [25]. A veterinarian examined the pigs every week.

Feed ingredients and fatty acid composition of the two experimental diets are shown in Table 1 and 4, respectively. The dietary treatment (diets produced at Borgen Aktiemolle, Andebu, Norway) was identical except for fat source; regular butter (Tine butter, Oslo, Norway) or CLA+VA rich butter (Table 4). The CLA+VA butter was specially produced for this experiment from milk from dairy cows that were receiving a cereal based commercial feed concentrate ( $8 \mathrm{~kg}$ per day), grass dominated pasture with white clover and supplemented with sunflower oil
Table 4: Composition of experimental diets, (g per $100 \mathrm{~g}$ dry feed).

\begin{tabular}{lcc}
\hline & REG $^{\mathrm{a}}$ & $\mathrm{CLA}+\mathrm{VA}^{\mathrm{b}}$ \\
\hline Ingredients & & \\
& & \\
Regular butter-fat & 16.16 & - \\
CLA rich butter-fat & - & 16.16 \\
Oat & 6.04 & 6.04 \\
Wheat bran & 39.7 & 39.7 \\
Soybean meal & 19.15 & 19.15 \\
Rapeseed meal & 3.97 & 3.97 \\
Sugarbeet pulp & 10.3 & 10.3 \\
Ground limestone & 1.36 & 1.36 \\
Monocalciumphosphate & 1.20 & 1.20 \\
Sodium chloride & 0.46 & 0.46 \\
SoftAcid & 0.88 & 0.88 \\
Microminerals, swine & 0.08 & 0.08 \\
L-lysine $^{\mathrm{c}}$ & 0.27 & 0.27 \\
DL-methionine & 0.16 & 0.16 \\
L-threonine $_{\text {D-cholinechloride }}$ & 0.115 & 0.115 \\
Vitaminpremix swine $^{\mathrm{d}}$ & 0.063 & 0.063 \\
& 0.053 & 0.053 \\
\hline
\end{tabular}

${ }^{a}$ Diet with regular butter as fat supplement

bDiet with a special CLA+VA rich butter as fat supplement 'Vitamins,: Providing the following amounts per $\mathrm{kg}$ of feed: Vitamin A $9000 \mathrm{lU}$; Vitamin $\mathrm{D}_{3} \mathrm{I} / 00 \mathrm{lU}$; Vitamin E I $10 \mathrm{mg}$; Vitamin $\mathrm{K}_{3} 2 \mathrm{mg}$; Thiamin $2 \mathrm{mg}$; Riboflavin $5 \mathrm{mg}$; Vitamin $\mathrm{B}_{6} 3 \mathrm{mg}$; Vitamin $\mathrm{B}_{12} 22 \mathrm{ug}$; Pantothenic acid $18 \mathrm{mg}$; Niacin $22 \mathrm{mg}$; Biotin $0.2 \mathrm{mg}$; Folate $1.5 \mathrm{mg}$. dMicrominerals: Providing the following amounts per kg of feed: $\mathrm{Zn}$ 112 mg; Fe 80 mg; Mn 60 mg; Cu 16 mg; I I mg; Se 0.4 mg.

(500 ml per day, containing 60\% 18:2, Karlshamn AB, Karlshamn, Sweden). The CLA+VA rich butter contained $2.1 \mathrm{~g}$ c9,t11-CLA and and $6.3 \mathrm{~g}$ VA per $100 \mathrm{~g}$ fat. The regular butter contained $0.6 \mathrm{~g}$ c9,t11-CLA and $1.5 \mathrm{~g}$ VA per $100 \mathrm{~g}$ fat. The average daily intake of $\mathrm{c} 9, \mathrm{t} 11$-CLA and VA in the CLA+VA treatment group was $5.0 \mathrm{~g}$ c9,t11-CLA, $15.1 \mathrm{~g}$ VA and in the REG group: $1.3 \mathrm{~g}$ c9,t11-CLA, $3.6 \mathrm{~g}$ VA.

\section{Study designs}

The experimental period lasted for three weeks. Twelve pigs were randomized into two groups $(n=6)$ and individually fed one of two diets; CLA+VA or REG. The pigs were weighed once every week and amount of feed was adjusted according to body weight. At feeding time, pigs were restrained in an individual feeding stall for about $1 /$ $2 \mathrm{~h}$, and feed intake was recorded.

Blood samples were obtained by vena cava puncture at the start and at the end of the experiment. Blood samples were taken after an overnight fasting in Na-heparin-, EDTAand empty vacuum tubes. Blood samples were immediately chilled on ice. Plasma and serum were obtained by low speed centrifugation for $20 \mathrm{~min}$ at $1700 \mathrm{~g}$. Plasma, serum and whole blood (heparin blood) were frozen and kept at $-80^{\circ} \mathrm{C}$ until analyzed. 


\section{Fatty acid analyses}

Fatty acid composition in serum, feed concentrate, palm oil and butter were determined by gas chromatography. Lipids were extracted according to Folch et al. [26]. For lipid extraction from serum a modified method was used: $0.2 \mathrm{ml}$ serum was mixed with $0.3 \mathrm{ml} 0.5 \mathrm{M} \mathrm{KH}_{2} \mathrm{PO}_{4}, 1.5$ $\mathrm{ml}$ chloroform and $0.5 \mathrm{ml}$ methanol. After centrifugation at $1700 \mathrm{~g}$ for 10 minutes, the lower phase was transferred to new tubes, the solvents were evaporated by $\mathrm{N}_{2}$, and lipids resolved in heptane. Fat from serum and diet were methylated by the method described by Kramer et al. [27], using both sodium methoxide and methanolic $\mathrm{HCl} 3 \mathrm{~N}$ (Supelco, PA, USA). Subsequently, the fatty acid methyl esters were analyzed using a Finnigan Focus gas chromatograph with a $100 \mathrm{~m}$ capillary column (CP Sil 88 WCOT, $100-\mathrm{m} \times 0.25 \mathrm{~mm}$, Chrompack, Middelburg, Netherland). Peak areas of fatty acids were used to calculate the amount of fatty acids ( $\mathrm{g} / 100 \mathrm{~g}$ fat) by theoretical response factors [28]. Standard fatty acids of known composition were run to identify the fatty acids in the samples. Plasma control samples were extracted, methylated and analysed by every $10^{\text {th }}$ sample.

\section{Plasma analyses}

The heparin-plasma analyses were carried out on a Cobas Mira autoanalyzer using the following kits: nonesterified fatty acids (NEFA) (NEFA C ACS-ACOD method. Wako Chemicals, VA, USA), triacylglycerol (Triglycerides 100, ABX diagnostics, Montpellier, France), total cholesterol (Cholesterol 100-250, ABX diagnostics, Montpellier, France), high density lipoprotein-cholesterol (HDL-cholesterol direct, ABX diagnostics, Montpellier, France) and glucose (Glucose HK 125 kit, ABX diagnostics, Montpellier, France). Low density lipoptotein-(LDL) cholesterol was calculated using the Friedewald equation [29]. The interassay coefficients of variation were the following: total cholesterol 2\%, HDL-cholesterol 5\%, triacylglycerols $3 \%$, NEFA $2.5 \%$.

LDL particle size distribution was determined by gradient gel electrophoresis as described by Sjogren et al. [5]. Briefly, a lipoprotein-rich fraction (containing very low density lipoprotein (VLDL) to LDL) was isolated from freshly thawed EDTA-plasma by adjusting the density to $1.070 \mathrm{~kg} / \mathrm{L}$ and subsequent ultracentrifugation (142500 g for $\left.22 \mathrm{~h}, 4^{\circ} \mathrm{C}\right)$. Recovery of total plasma apoB was $77 \pm$ $12 \%(\mathrm{n}=8)$. The lipoprotein-rich fraction was applied to a $3-7.5 \%$ polyacrylamide gel together with standard lipoproteins (isolated human $\mathrm{Lp}(\mathrm{a})$ and $\mathrm{LDL}$ ) and proteins (thyroglobulin mono- and dimer, Pharmacia, LKB, Stockholm, Sweden) of known size and run for $20 \mathrm{~h}$ at $80 \mathrm{~V}$. Gels were stained for protein $(0.04 \%$ Coomassie Brilliant Blue, Serva, Heidelberg, Germany) and analyzed using a Fuji LAS-1000 system and Image Gauge software to give peak particle size of LDL and relative distribution of LDL in predefined subfractions with cut-offs: LDL-I (27.0-25.0 $\mathrm{nm})$, LDL-II (25.0-23.5 nm), LDL-III (23.5-22.5 nm) and LDL-IV (22.5-21.0 nm), corresponding to densities of 1.006-1.030, 1.030-1.040, 1.040-1.050 and 1.050$1.063 \mathrm{~kg} / \mathrm{L}$, respectively. A density of $1.040 \mathrm{~kg} / \mathrm{L}$ is a classic boundary for dividing LDL into large and small particles [30] rendering LDL subclasses III and IV as small dense LDL with this method.

\section{Statistical methods}

The results of the plasma and serum analyses are presented as mean values, and standard deviation and p-values are given. Data were analyzed by using the statistical package in Microsoft Office Excel, 2003, using TTEST, two-tailed distribution and two-sample equal variance.

\section{Competing interests}

The authors declare that they have no competing interests.

\section{Authors' contributions}

AH, PS, NH, NPK, OT, NF, HM, ASB, ES-O and OMH have made substantive intellectual contributions to the study concerning conception and design, acquisition of data and analyses and interpretation of the data.

\section{Acknowledgements}

We are grateful to Tine BA, Oslo, Norway for support and providing the butter and funds for the laboratory analyses in this study, several researchers at the Norwegian University of Life Sciences for spending time working with the study and writing the manuscript, personnel working at the animal unit (SHF) for conducting the feeding experiments, staff at the Norwegian School of Veterinary Science, Oslo, Norway for taking blood samples, the staff working at the laboratories at the Norwegian University of Life Sciences for blood analyses and the research staff at Karolinske Institutet, Sweden for providing the LDL particle size analyses.

The sources of funding in study design and practical work, manuscript preparation and interpretation of data for each author in the study: $\mathrm{AH}, \mathrm{NH}$, NPK, HM, OT, OMH: Norwegian University of Life Sciences, Aas, Norway, PS: Karolinska Institutet, Stockholm, Sweden, ASB and ESO; Tine AB, Norway.

\section{References}

I. Sandstrom B, Marckmann P, Bindslev N: An eight-month controlled study of a low-fat high-fibre diet: effects on blood lipids and blood pressure in healthy young subjects. Eur J Clin Nutr 1992, 46:95-109.

2. Elwood PC, Pickering JE, Hughes J, Fehily AM, Ness AR: Milk drinking, ischaemic heart disease and ischaemic stroke II. Evidence from cohort studies. Eur J Clin Nutr 2004, 58:7 I8-724.

3. Seidel C, Deufel T, Jahreis G: Effects of fat-modified dairy products on blood lipids in humans in comparison with other fats. Ann Nutr Metab 2005, 49:42-48.

4. Tholstrup T, Hoy CE, Andersen LN, Christensen RD, Sandstrom B: Does fat in milk, butter and cheese affect blood lipids and cholesterol differently? J Am Coll Nutr 2004, 23:169- I76.

5. Sjogren P, Rosell M, Skoglund-Andersen M, Zdravkovic S, Vessby B, deFaire U, Hamsten A, Hellenius ML, Fisher R: Milk-derived fatty acids are associated with a more favorable LDL particle size distribution in healthy men. J Nutr 2004, 134:1729-35.

6. de Graaf J, Hak-Lemmers HL, Hectors MP, Demacker PN, Hendriks JC, Stalenhoef AF: Enhanced susceptibility to in vitro oxidation 
of the dense low density lipoprotein subfraction in healthy subjects. Arterioscler Thromb 1991, I I:298-306.

7. Kramer JK, Cruz-Hernandez C, Deng Z, Zhou J, Jahreis G, Dugan ME: Analysis of conjugated linoleic acid and trans I8:I isomers in synthetic and animal products. Am J Clin Nutr 2004, 79: I I37S-1 I 45S.

8. Tricon S, Burdge GC, Kew S, Banerjee T, Russell J], Jones EL, Grimble RF, Williams CM, Yaqoob P, Calder PC: Opposing effects of cis-9, trans-II and trans-10, cis- 12 conjugated linoleic acid on blood lipids in healthy humans. Am J Clin Nutr 2004, 80:6 I4-20.

9. Tricon S, Burdge GC, Jones EL, et al.: Effects of dairy products naturally enriched with cis-9, trans-I I conjugated linoleic acid on the blood lipid profile in healthy middle-aged men. Am J Clin Nutr 2006, 83:744-53.

10. Valeille K, Gripois D, Blouquit MF, Souidi M, Riottot M, Bouthegourd JC, Serougne C, Martin JC: Lipid atherogenic risk markers can be more favourably influenced by the cis-9, trans-I I-octadecadienoate isomer than a conjugated linoleic acid mixture or fish oil in hamsters. Br J Nutr 2004, 91 : I9I-9.

II. Turpeinen AM, Mutanen M, Aro A, Salminen I, Basu S, Palmquist DL, Griinari JM: Bioconversion of vaccenic acid to conjugated linoleic acid in humans. Am J Clin Nutr 2002, 76:504-10.

12. Jenkins TC, Wallace RJ, Moate PJ, Mosley EE: Board-invited review: Recent advances in biohydrogenation of unsaturated fatty acids within the rumen microbial ecosystem. J Anim Sci 2008, 86:397-412

13. Bu DP, Wang JQ, Dhiman TR, Liu SJ: Effectiveness of oils rich in linoleic and linolenic acids to enhance conjugated linoleic acid in milk from dairy cows. J Dairy Sci 2007, 90:998-I007.

14. Willett WC, Stampfer MJ, Manson JE, et al.: Intake of trans fatty acids and risk of coronary heart disease among women. Lancet $|993,34|: 58 \mid-5$.

15. Park Y, Albright KJ, Storkson JM, Liu W, Cook ME, Pariza MW: Changes in body composition in mice during feeding and withdrawal of conjugated linoleic acid. Lipids 1999, 34:243-8.

16. Dugan ME, Aalhus JL, Kramer JK: Conjugated linoleic acid pork research. Am J Clin Nutr 2004, 79(6 Suppl): |2 I 2S- I2 I6S.

17. Leibbrandt VD, Ewan RC, Speer VC, Zimmerman DR: Effect of age and calorie: Protein ratio on performance and body composition of baby pigs. J Animal Sci 1975, 40:1070-76.

18. Smith DR, Knabe DA, Cross HR, Smith SB: A diet containing myrisitoleic plus palmitoleic acids elevates plasma cholesterol in young growing swine. Lipids 1996, 31:849-58.

19. Smedman AE, Gustafsson IB, Berglund LG, Vessby BO: Pentadecanoic acid in serum as a marker for intake of milk fat: relations between intake of milk fat and metabolic risk factors. Am J Clin Nutr 1999, 69:22-9.

20. Wolfram G: Dietary fatty acids and coronary heart disease. Eur J Med Res 2003, 8:32I-4.

21. Luhman CM, Faidley TD, Beitz DC: Postprandial lipoprotein composition in pigs fed diets differing in type and amount of dietary fat. J Nutr 1992, 122:120-7.

22. Ascherio A: Trans fatty acids and blood lipids. Atheroscler Suppl 2006, 7:25-7.

23. Campos H, Blijlevens E, McNamara JR, Ordovas JM, Posner BM, Wilson PW, Castelli WP, Schaefer El: LDL particle size distribution. Results from the Framingham Offspring Study. Arterioscler Thromb 1992, 1 2:1410-9.

24. Dreon DM, Fernstrom HA, Campos $H$, Blanche P, Williams PT, Krauss RM: Change in dietary saturated fat intake is correlated with change in mass of large low-density-lipoprotein particles in men. Am J Clin Nutr 1998, 67:828-36.

25. NRC: Nutrient requirements of swine. 9th edition. National Academy Press, Washington, D.C; 1988.

26. Folch J, Lees M, Stanley GHS: A simple method for the isolation and purification of total lipids from animal tissues. J Biol Chem 1957, 226:497-509.

27. Kramer JKG, Fellner V, Dugan MER, Sauer FD, Mossoba MM, Yurawecz MP: Evaluating acid and base catalyst in the methylation of milk and rumen fatty acids with special emphasis on conjugated dienes and total trans fatty acids. Lipids 1997, 32:1219-28.

28. Ackman RG, Sipos JC: Flame ionization detector response for the carbonyl carbon atom in the carboxyl group of fatty acids and esters. J Chromatogr 1964, 16:298-305.
29. Friedewald WT, Levy RI, Fredrickson DS: Estimation of the concentration of low-density lipoprotein cholesterol in plasma, without use of the preparative ultracentrifuge. Clin Chem 1972, 18:499-502.

30. Skoglund-Andersson C, Tang R, Bond MG, deFaire U, Hamsten A, Karpe $F$ : LDL particle size distribution is associated with carotid intima-media thickness in helathy 50-year-old men. Arterioscler Thromb Vasc Biol 1999, 19(10):2422-30.
Publish with Biomed Central and every scientist can read your work free of charge

"BioMed Central will be the most significant development for disseminating the results of biomedical research in our lifetime. "

Sir Paul Nurse, Cancer Research UK

Your research papers will be:

- available free of charge to the entire biomedical community

- peer reviewed and published immediately upon acceptance

- cited in PubMed and archived on PubMed Central

- yours - you keep the copyright 